\title{
Analysis on Construction Management of Small Water Conservancy Projects in the Countryside of China
}

\author{
Xuezhen Shuang ${ }^{1}$, Guangbin $\mathrm{Yu}^{2}$ \\ ${ }^{1}$ Sichuan Water Conservancy vocational College, Chengdu, 611830, China \\ ${ }^{2}$ Armed Police Hydropower ninth detachment, Chengdu, 611130, China
}

Keywords: Countryside, Small water conservancy project, Construction management

\begin{abstract}
With the importance attached to issues of agriculture by China, there are more and more infrastructure construction projects in the countryside. Water conservancy project is an important one. Such infrastructure can not only promote sustained and stable development of the countryside, but also guarantee food security of China correspondingly and improve rural economic development and incomes of peasants. However, small water conservancy projects in the countryside of China have some problems which might cause the failure of rural development to keep up with the step and demand of the era. Therefore, it is required to take corresponding measures specific to these problems so as to promote the development of China. This paper analyzes problems of small water conservancy projects in the countryside of China and strives to improve the work efficiency of engineering construction management.
\end{abstract}

\section{Introduction}

With the constant issuance of preferential policies related to rural construction in China, rural development and incomes of peasants have been improved constantly. To further promote rural construction in China, the state has more inputs into rural infrastructure. However, due to inadequate understanding of the construction of small water conservancy projects in 1990s, the construction management of rural small water conservancy projects has many deficiencies which cause the failure to guarantee the progress, quality and benefit of engineering construction and meanwhile hinder rural construction. ${ }^{[1]}$ Therefore, solving problems existing in the construction management of small water conservancy projects in the countryside of China and improving the quality, progress and economic benefit of water conservancy projects is the emphasis in the construction of rural small water conservancy projects.

\section{Significance of construction of rural small water conservancy projects}

\section{Promote rural and social development}

Small water conservancy projects in the countryside contain many constituent parts including small bridges, culverts, driven wells and channels. These small water conservancy facilities help peasants in water storage and diversion in their life and production process. Therefore, these water conservancy projects often include water storage and diversion facilities and water transport and distribution facilities. ${ }^{2]}$ These small water conservancy projects greatly promote Chinese rural development and guarantee the production safety of crops and sustained growth of agricultural benefit. Moreover, peasants' incomes are improved effectively and the countryside achieves sustained development. In addition, rural small water conservancy projects also improve the life quality of peasants. Therefore, the construction of small water conservancy projects in the countryside promotes social and economic development and enables the smooth implementation of the construction of new socialist countryside.

\section{Important approaches for environmental protection and rural construction}

The construction of water conservancy projects is often great help for environmental protection in China and meanwhile can promote the construction of new socialist countryside. In most rural 
regions in China especially remote countryside, drought often occurs due to the influence of environment and climate and water resources are lacking. There are very few drinking water resources. All this greatly hinders rural construction and the normal life of peasants. However, the construction of small water conservancy projects can help to improve the quality of rural environment and the phenomenon of lacking water resources in the countryside of northwest region and meanwhile guarantee the living and production environment of Chinese rural residents so as to accelerate agricultural development and improve peasants' incomes and economic benefit brought by agriculture.

\section{Problems in construction of small water conservancy projects in the countryside of China}

There are many problems in the construction and management of small water conservancy projects in the countryside of China. Corresponding discussions and improvement of these problems can guarantee the smooth exertion of functions of water conservancy construction.

\section{Old facilities}

The first problem existing in small water conservancy projects in the countryside of China is old or aged facilities of water conservancy projects. Small water conservancy projects in the countryside of China were basically constructed in 1960s or 1970s. Construction equipment of water conservancy projects and economic and technological level were limited at that time. Therefore, small water conservancy projects constructed at that time do not have complete functions and there are many problems in completed water conservancy projects. ${ }^{[3]}$ These problems include disordered distribution of small water conservancy projects in the countryside, low engineering technical content, incomplete relevant infrastructure, low quality of engineering construction and poor fastness. Moreover, these water conservancy projects have operated for a long time and most of them haven't been renovated correspondingly after completion. Therefore, most of them are in bad repair and have problems such as damage or reduction of work efficiency. All this hinders the development of benefits and functions of water conservancy projects.

\section{Few new projects}

After China put emphasis on agricultural development and peasants' incomes, inputs into agricultural construction and water conservancy construction have constantly increased and great support has been provided in funds, technology and planning. However, most of such support is applied to the construction of flood control facilities or large projects. There are still very few inputs into the construction of small water conservancy projects. Especially in some remote rural regions with hostile environment or backward construction, inputs of the government and the state into rural water conservancy construction are far from enough compared to actual demands of these water conservancy projects. To guarantee the smooth construction of water conservancy projects, further promote rural development and help to get rid of poverty, the remaining funds required for the construction of water conservancy projects have to be provided by peasants. It is very difficult for poor rural regions. In addition, some peasants think that water conservancy construction is a problem to be solved by relevant departments of the state and the government. Therefore, many new water conservancy projects cannot be implemented smoothly. Small water conservancy projects with advanced technology, process and equipment cannot develop in rural regions. These conditions restrict the construction of small water conservancy projects in China.

\section{Backward management work}

With the implementation of production responsibility system in rural regions, though responsibilities of peasants in the production process are specified and they can be responsible for their own work, there are certain disadvantages for public construction and facilities. That is, though peasants' awareness of individual responsibility has been improved, their sense of collectivity and unity becomes weaker. For public infrastructure such as water conservancy engineering facilities, people might only have the awareness of water utilization and lack the awareness of protecting and 
managing relevant facilities of water conservancy projects. This results in weak management awareness of peasants and the failure to effectively manage and protect the construction of small water conservancy projects. Besides, as relevant system or policies of the government about the construction of water conservancy projects are not implemented properly, the management, responsibilities and benefit distribution about the construction of rural small water conservancy projects are undefined, which easily cause the separation of construction and management of water conservancy projects. After the completion of construction of small water conservancy projects, peasants are only willing to enjoy their benefits rather than conduct management and maintenance.

Moreover, some peasants think that the government should be responsible for the maintenance and management of water conservancy projects. Therefore, they are unwilling to maintain and manage the construction of water conservancy projects and even damage water conservancy facilities arbitrarily. Such behaviors hinder the exertion of benefit and functions of water conservancy projects seriously and cause economic loss of rural regions and the state.

\section{Approaches for strengthening construction management of rural small water conservancy projects}

To solve various problems existing in the construction of rural small water conservancy projects, it is required to establish corresponding strategies specific to problems faced by rural development and the construction of rural small water conservancy projects and improve the management of construction of such projects.

\section{Strengthen supervision on construction quality}

As water conservancy projects play a positive role in agricultural development, peasants' incomes and environmental protection, engineering quality is vital. ${ }^{[4]}$ In the construction of water conservancy projects, engineering construction is the most important link, which influences the overall quality of water conservancy projects. In addition, engineering construction can help to achieve its real purpose and give full play to the function and benefit of water conservancy projects. Therefore, to achieve purposes above, it is required to conduct corresponding quality supervision on the construction process of rural small water conservancy projects and guarantee that the construction follows engineering design and relevant laws and standards. Meanwhile, construction unit shall manage and supervise the construction process effectively, put engineering quality in the first place of construction and take drastic measures and force to stop the project or rework relevant parts once finding any behavior violating relevant provisions and standards or unqualified construction quality in the process of construction quality management and supervision. In this process. Construction unit shall regard engineering quality as the primary task of engineering construction and cooperate with relevant supervision and management personnel for improving engineering quality once any quality problem is found.

\section{Attach importance to project tendering work}

The overall quality of water conservancy projects is greatly related to construction quality and unit. Therefore, it is required to select construction unit strictly before the construction of rural small water conservancy projects, and compare personnel quality, construction equipment, experience and credibility of construction units and select one with great advantages in these aspects for construction during project tendering. According to provisions of relevant departments of China, tendering of the construction of water conservancy projects should use equity, fairness and openness as basic principles and tendering units should have a healthy competitive environment, which can not only guarantee the selection of a construction unit meeting the standard, but also avoid the occurrence of "projects with human relationship" and vicious competition in the tendering process, improve the comprehensive ability of construction unit, guarantee transparency in the construction of water conservancy projects and create a good market and competitive environment. 


\section{Conduct scientific management}

To correspond to social and scientific progress, it is required to change the previous traditional management method for small water conservancy projects, use a scientific and effective management method for water conservancy project management, help the implementation of rural small water conservancy projects, improve the efficiency of management and construction and create better development conditions for Chinese rural residents. Therefore, after the completion of construction of such projects, it is required to transfer these assets to the relevant unit and person in charge in time and issue relevant property right and use certificate for the use of water conservancy project facilities so that projects can get effective operation management in the operational process and water conservancy facilities can develop healthily and smoothly. Meanwhile, relevant management methods should be adopted for water conservancy projects according to rural situations in combination with the will of peasants. Water conservancy projects should be able to make profits and meet requirements of the society and market economy.

\section{Increase input into water conservancy projects}

A lot of material, financial and human resources should be used in the construction of water conservancy facilities. Therefore, the strong support of the government is required for guaranteeing the smooth implementation of rural small water conservancy projects. ${ }^{[5]}$ The government should increase inputs into the construction of relevant water conservancy projects, establish feasible policies and transfer the emphasis of relevant rural construction to the construction of infrastructure such as water conservancy construction. It is required to increase inputs into rural water conservancy projects, develop more water conservancy projects and repair and maintain previous old water conservancy facilities. In addition, local governments should fully arouse the enthusiasm of peasants and make them engaged in the construction of water conservancy projects positively. Construction unit shall report the project situation in time.

\section{Strengthen talent training}

Water conservancy construction cannot be separated from relevant talents. Therefore, more importance should be attached to the training of water conservancy construction talents. It is also required to establish a complete and effective method for talent training and select talents according to the actual situation of China and the development status of rural water conservancy. Meanwhile, in-service staff responsible for the construction of water conservancy projects should be provided with periodical training so as to learn the most advanced knowledge and technology and avoid being isolated from the society. In addition, workers should be distributed reasonably so that they can give a full play to their functions at their posts. During talent recruitment, construction unit of water conservancy projects should conduct strict examination and recruit talents meeting the demand of the unit and the society so as to conduct project construction with the full use of human resources.

\section{Conclusion}

In all ages, it is very important to develop water conservancy construction and prevent natural hazards such as flood, which influence both social and economic development and the daily life of people. Therefore, it is vital to strengthen the construction of water conservancy projects. Countryside and agriculture is the emphasis of social and economic development. The improvement of peasants' incomes and agricultural construction is always the priority among priorities of social work. The construction of water conservancy projects can not only reduce natural hazards, but also provide effective approaches for rural development of China. Therefore, analyzing the status of construction of small water conservancy projects in the countryside of China and solving existing problems according to actual situation can effectively exert the function of water conservancy projects in agricultural production and social development. 


\section{References}

[1] Wang Youhui. Research on Reform of Construction Management of Rural Small Water Conservancy Projects. Heilongjiang Science and Technology of Water Conservancy, 2012,40(7):247-248.

[2] Li Hongbing, Huang Dong. Brief Discussions on Problems in Construction Management of Rural Small Water Conservancy Projects and Countermeasures. Business Conditions, 2012(17):173-173.

[3] Li Haixia. Thinking on Construction Management of Rural Small Water Conservancy Projects. Beijing Agriculture, 2012,(21):218.

[4] Liu Xuewen. Research on Strengthening Construction Management of Rural Small Water Conservancy Projects. Architectural Engineering Technology and Design, 2015(8):1447-1447.

[5] Wu Zongyuan. Humble Opinions on Management Status of Rural Small Water Conservancy Projects and Development Trend. Scientific and Technological Innovation and Application, 2012(12):130-130. 